\title{
Review Article \\ Complementary Roles of Orexin and Melanin-Concentrating Hormone in Feeding Behavior
}

\author{
Jessica R. Barson, Irene Morganstern, and Sarah F. Leibowitz \\ Laboratory of Behavioral Neurobiology, The Rockefeller University, 1230 York Avenue, New York, NY 10065, USA \\ Correspondence should be addressed to Sarah F. Leibowitz; leibow@mail.rockefeller.edu
}

Received 29 March 2013; Accepted 21 June 2013

Academic Editor: Carlos Dieguez

Copyright ( 2013 Jessica R. Barson et al. This is an open access article distributed under the Creative Commons Attribution License, which permits unrestricted use, distribution, and reproduction in any medium, provided the original work is properly cited.

\begin{abstract}
Transcribed within the lateral hypothalamus, the neuropeptides orexin/hypocretin (OX) and melanin-concentrating hormone $(\mathrm{MCH})$ both promote palatable food intake and are stimulated by palatable food. While these two neuropeptides share this similar positive relationship with food, recent evidence suggests that this occurs through different albeit complementary effects on behavior, with OX promoting food seeking and motivation for palatable food and $\mathrm{MCH}$ functioning during ongoing food intake, reinforcing the consumption of calorically dense foods. Further differences are evident in their effects on physiological processes, which are largely opposite in nature. For example, activation of OX receptors, which is neuronally excitatory, promotes waking, increases energy expenditure, and enhances limbic dopamine levels and reward. In contrast, activation of MCH receptors, which is neuronally inhibitory, promotes paradoxical sleep, enhances energy conservation, reduces limbic dopamine, and increases depressive behavior. This review describes these different effects of the neuropeptides, developing the hypothesis that they stimulate the consumption of palatable food through excessive seeking in the case of OX and through excessive energy conservation in the case of MCH. It proposes that $\mathrm{OX}$ initiates food intake and subsequently stimulates $\mathrm{MCH}$ which then acts to prolong the consumption of palatable, energy-dense food.
\end{abstract}

\section{Introduction}

The hypothalamus has long been known to play an important role in feeding behavior. As far back as 1951, Anand and Brobeck [1] reported that bilateral destruction of the lateral hypothalamus (LH) in rats resulted in the complete absence of eating, leading them to term this area of the brain the "feeding center." Shortly thereafter, Delgado and Anand [2] reported that electrical stimulation of the LH in cats resulted in a 1,000 percent increase in total food intake. Interestingly, rats will work to receive electrical stimulation of the LH ("self-stimulation"), indicating that this nucleus also plays a function in reward, but excessive food intake leads them to decrease their rate of self-stimulation by half [3]. While a number of classical neurotransmitters have been implicated in LH-induced feeding, the discovery of neuropeptides in the brain [4] has led researchers to consider several of these local neuromodulatory neurochemicals as major players in feeding and reward.
Two neuropeptides transcribed in the $\mathrm{LH}$ are now understood to play significant roles in feeding and reward. The peptides, orexin A (OX-A) and orexin B (OX-B) (also called hypocretin 1 and hypocretin 2), are cleaved from the 130amino acid precursor neuropeptide preproorexin (ppOX), which was independently isolated by two research groups in $1998[5,6]$. Neurons containing orexin (OX) mRNA (about 6700 in the rat) [7] lie exclusively within the hypothalamus, spanning the dorsomedial hypothalamic nucleus through the perifornical area and into the lateral hypothalamic area $[5,6]$. This peptide was immediately recognized for its ability to stimulate food consumption, leading one research group to name the peptide OX after the Greek word for appetite, orexis [6]. The peptide melanin-concentrating hormone $(\mathrm{MCH})$, isolated from the salmon pituitary in 1983 as an antagonist of alpha-MSH-induced skin darkening [8], was recognized for its role in feeding in 1996 [9]. Neurons containing mRNA for the 165 -amino acid precursor prepro-melanin-concentrating hormone (ppMCH, numbering about 12300 in the rat) [7] 
are distinct from but adjacent to those containing OX, lying predominantly in the LH but also in the perifornical area and subzona incerta [10].

It is now well-established that $\mathrm{OX}$ and $\mathrm{MCH}$ can act as orexigenic neuropeptides, affecting both food intake and processes of reward that influence food intake. Despite their similar relationship with consumption, these peptides appear to act in complementary rather than redundant ways with food intake, and in fact have largely opposite roles in physiological processes and reward-related behavior. Here, we review the current knowledge about the relationship of these peptides with feeding, while providing a brief discussion of their other actions that may elucidate the mechanisms through which they promote food intake.

\section{Receptor Function}

2.1. Intracellular Effects of Receptor Binding. As with all neuropeptides, the receptors for $\mathrm{OX}$ and $\mathrm{MCH}$ are $\mathrm{G}$ proteincoupled receptors. There are two known receptors for OX, called the orexin 1 receptor (OX1R) and orexin 2 receptor (OX2R), or the hypocretin 1 and 2 receptors. While OX1R binds to OX-A with an affinity that is two to three orders of magnitude greater than for OX-B, OX2R binds to OX$A$ and OX-B with nearly equal affinity [6]. Orexin receptor binding largely results in neuronal excitation, a rise in cytoplasmic calcium, with OX1R activating $\mathrm{G}_{\mathrm{q}}$ subunits and OX2R activating $G_{q}$ but also $G_{i / o}$ subunits $[6,11]$.

Depending on the species studied, there are either one or two receptors for $\mathrm{MCH}$. Rats, mice, hamsters, guinea pigs, and rabbits have only one identified $\mathrm{MCH}$ receptor, MCHR1, but humans, rhesus monkeys, dogs, and ferrets also have a functional $\mathrm{MCH}$ receptor 2 [12]. As with OX2R, MCHR1 binding appears to activate both $\mathrm{G}_{\mathrm{i} / \mathrm{o}}$ and $\mathrm{G}_{\mathrm{q}}$ subunits [13], although the major effect of MCHR1 binding is a decrease in cyclic AMP levels $[14,15]$. Thus, OX and $\mathrm{MCH}$ receptor binding has largely opposite effects on neuronal excitation.

2.2. Projections and Receptor Localization. Projections from $\mathrm{OX}$ - and $\mathrm{MCH}$-containing neurons terminate in many of the same brain areas, which may explain why these neuropeptides affect a number of the same behaviors. These brain areas include the locus coeruleus, hippocampus, thalamus, nucleus accumbens (NAc), ventral tegmental area (VTA), amygdala, cortex, and various nuclei of the hypothalamus $[16,17]$. The receptors for $\mathrm{OX}$ and $\mathrm{MCH}$ are also located in these same brain areas $[18,19]$. Interestingly, while OX1R and OX2R are often found in the same nuclei, they tend to predominate in different subregions of those nuclei. For example, in the hypothalamus, OX1R is most dense in the anterior hypothalamic nucleus while sparse in the LH and absent from the arcuate and paraventricular nuclei, and $\mathrm{OX} 2 \mathrm{R}$ is sparse in the anterior hypothalamic nucleus while dense in the LH, arcuate, and paraventricular nuclei [18].

2.3. Interaction between Orexin and $M C H$. In support of the idea that $\mathrm{OX}$ and $\mathrm{MCH}$ work in a complementary or even opposite manner, these two peptides have been shown to interact directly with each other. Neurons containing OXA or MCH are found to contact each other [20], and OX1R has been described on MCH neurons of the LH [21]. In slice preparation, the addition of OX-A or OX-B evokes long-lasting membrane depolarization and increases spike frequency of $\mathrm{MCH}$ cells [22], and the addition of $\mathrm{MCH}$ inhibits OX-A-induced spike frequency of OX neurons [23]. Therefore, while OX directly excites $\mathrm{MCH}$ neurons, $\mathrm{MCH}$ prevents excitation of OX neurons.

\section{Physiological Effects}

The OX and $\mathrm{MCH}$ systems largely play opposing roles in the regulation of the sleep-wake cycle and energy balance. Whereas OX promotes wakefulness and energy expenditure and is inhibited by a rise in glucose levels, $\mathrm{MCH}$ plays a role in sleep and energy conservation while being activated by glucose.

3.1. Role in Sleep-Wake Cycle. The firing of OX neurons is robustly tied to arousal during the sleep-wake cycle. These neurons discharge during wakefulness, cease firing with sleep onset, remain silent during slow-wave sleep, discharge periodically during paradoxical (or rapid eye movement, REM) sleep, and begin firing again prior to the transition from REM sleep to waking $[24,25]$. They can fire during sleep when an arousing sound stimulus is presented $[25,26]$. In support of a direct role for OX in promoting arousal, injection of OX-A or OX-B into the lateral ventricles increases waking and decreases slow-wave and REM sleep [27], while peripheral injection of the OX2R antagonist JNJ-10397049 but not OX1R antagonist SB-408124 decreases the latency for persistent sleep [28]. Transgenic mice lacking the ppOX gene display behaviors strongly resembling narcolepsy, exhibiting frequent periods of behavioral arrest during the dark (active) but not light phase [29]. In fact, the link between OX and narcolepsy was established soon after the neuropeptide's discovery, with an autosomal recessive mutation of OX2R identified in canine narcolepsy [30] and human narcoleptics found to have a reduction, as much as $95 \%$, in the number of OX neurons [31]. Thus OX, acting through OX2R, functions to consolidate the waking state.

In contrast to $\mathrm{OX}, \mathrm{MCH}$ has been linked with sleep, particularly with paradoxical sleep. Rather than discharging during wakefulness, $\mathrm{MCH}$ neurons fire maximally during REM sleep and occasionally during slow-wave sleep [32]. In support of a direct role for $\mathrm{MCH}$ in promoting sleep, injection of $\mathrm{MCH}$ into the lateral ventricles increases the quantity of paradoxical and slow-wave sleep [33], while both $\mathrm{MCH}$ and MCHR1 knockout mice show increased wakefulness [34, 35]. On the other hand, $\mathrm{MCH}$ does not appear to play a role in narcolepsy. Human narcoleptics show normal numbers of $\mathrm{MCH}$ neurons along with reduced numbers of OX neurons $[31,36]$, and there is no evidence to date linking mutations of MCHR1 to narcolepsy.

3.2. Role in Energy Balance. Orexin and $\mathrm{MCH}$ also largely play opposite roles in energy balance, in parallel with their 
roles in physiological arousal. For example, intracerebroventricular (ICV) injection of OX potently increases oxygen consumption, and transgenic mice overexpressing ppOX are resistant to high-fat diet-induced obesity due to their increased energy expenditure and reduced fat consumption [37]. A specific role for OX2R in promoting energy expenditure is supported by evidence that this resistance to dietary obesity is found in OX overexpressors lacking OX1R but not in those lacking OX2R and that chronic ICV injection of [Ala11, D-Leu15] OX-B, which binds to OX2R, prevents the development of fat-induced obesity [37]. In contrast to $\mathrm{OX}, \mathrm{MCH}$ promotes energy conservation. In addition to the small decrease in oxygen consumption that occurs with ICV injection of $\mathrm{MCH}[38,39]$, mice overexpressing the ppMCH gene show increased body weight on a standard diet [40], while those lacking $\mathrm{MCH}$ show both decreased body weight and food intake [41, 42]. Interestingly, despite hyperphagia, mice lacking MCHR1 also exhibit decreased body weight on standard chow and are less susceptible to high-fat diet-induced obesity, likely as a consequence of their hyperactivity [43]. Also, genetically obese ob/ob and $\mathrm{db} / \mathrm{db}$ mice are reported to have elevated MCH mRNA and peptide levels [44], and chronic ICV MCH increases caloric efficiency and body fat mass while an MCHR1 antagonist decreases them [45]. Together, these results support the idea that $\mathrm{OX}$ promotes energy expenditure, while $\mathrm{MCH}$ reduces it.

3.3. Regulation by Glucose. The activity of $\mathrm{OX}$ and $\mathrm{MCH}$ neurons is also regulated by energy status as indicated by levels of glucose. A physiological rise in glucose, which would occur after normal meal ingestion, is found to inhibit the electrical excitability of OX neurons in the mouse LH [46, 47]. This is in contrast to nearby $\mathrm{MCH}$ neurons, which are excited by elevated glucose levels $[46,48]$. Whereas these two changes together might reflect a role for these peptides in energy balance, the evidence described below suggests that they may similarly be seen as promoting intake of a currently consumed food.

\section{Role in Food Intake}

Despite their discordant roles in behavioral state and energy balance, $\mathrm{OX}$ and $\mathrm{MCH}$ both act as orexigenic neuropeptides. While this effect can be seen with standard laboratory chow, it is even stronger with palatable food. A notable feature of palatable food is that it is generally overconsumed, such that homeostatic signals are overridden during the course of a meal, resulting in prolonged and excessive intake. Importantly, in addition to driving intake, both $\mathrm{OX}$ and $\mathrm{MCH}$ are themselves stimulated by the consumption of palatable food, further contributing to its overconsumption. While similar in this positive feedback circuit, the stimulation of food intake induced by $\mathrm{OX}$ and $\mathrm{MCH}$ appears to occur through different, complementary mechanisms. As described later, OX may increase the seeking and motivation to consume palatable food, whereas $\mathrm{MCH}$ appears to increase the reinforcing effects of caloric intake.
4.1. Effects of Peptides on Food Intake. A large body of evidence linking $\mathrm{OX}$ and $\mathrm{MCH}$ with food intake comes from studies of transgenic mice overexpressing or lacking the genes for these neuropeptides and also from studies of outbred rats using injections of the peptides or their antagonists.

4.1.1. Orexin. As described in the Introduction, the orexigenic effect of OX was noted at the same time that this peptide was first described [6], although the magnitude of its effect is much lower than that of the highly orexigenic neuropeptide Y (NPY) [49]. Under certain paradigms, OX can promote intake of standard laboratory chow in rats and mice. This has been shown for central injection of OX-A into the lateral ventricles [50], hypothalamic paraventricular nucleus $[49,51], \mathrm{LH}$ or perifornical area $[51,52]$, as well as the NAc shell $[53,54]$. While the feeding effects of ICV injection with OX-B are sometimes as potent as those of OX-A [50, 52], these effects of OX appear to occur primarily through OX1R, as a stimulatory effect on food intake with injections into specific brain sites has yet to be observed with OX-B $[51,52]$. Notably, ppOX knockout mice show no difference in chow intake when compared to their wild-type littermates $[55,56]$, supporting the idea that this peptide may not be necessary for normal food intake.

A body of evidence indicates that the orexigenic effects of OX are far more robust with palatable food. In a variety of paradigms, peripheral administration of the OX1R antagonist SB-334867 is found to significantly suppress intake of palatable, high-fat food [57-59], and injection of OX-A into the third cerebral ventricle selectively increases intake of a highfat diet more than a high-carbohydrate diet [60]. Whereas peripheral SB-334867 administration does not consistently decrease sucrose self-administration in rats [61-63], ad libitum fed ppOX knockout mice consume less of a sucrose solution than their wild-type littermates [64]. This link between OX and palatable food intake, similar to chow intake, appears to be mediated by OX1R, with the OX1R antagonist SB-649868 but not OX2R antagonist JNJ-10397049 found to decrease binge eating of a high-fat, high-sucrose food in female rats [65].

The ability of OX to increase food intake may occur in large part through its stimulation of arousal as well as an increase in motivation, particularly when palatable food is involved. While similar to wild-type littermates in their chow intake, ppOX knockout mice exhibit deficits in their ability to learn about the availability of food. Under mild food restriction, they demonstrate delayed acquisition of operant responding for chow [56] and significantly diminished foodanticipatory activity prior to scheduled feeding $[55,66]$. Interestingly, conditional OX gene knockdown via RNAi in normal mice causes decreased responding for chow under both variable and progressive ratio schedules [56], suggesting that OX normally promotes reinforcement-related aspects of food intake. The particular reinforcement-related aspect may be motivation, as $\mathrm{OX} 1 \mathrm{R}$ binding largely appears to affect palatable food intake by increasing the motivation for food. Peripheral administration of the OX1R antagonist SB334867 decreases progressive and fixed ratio responding for a 
high-fat diet and for sucrose [57, 61, 62], while third ventricle injection of OX-A increases progressive ratio responding for sucrose [57]. Similarly, SB-334867 significantly decreases cueinduced reinstatement of sucrose seeking [61]. Together, these results suggest that $\mathrm{OX}$, acting at $\mathrm{OX} 1 \mathrm{R}$, promotes food intake by increasing the motivation for food reward.

4.1.2. $\mathrm{MCH}$. The orexigenic effect of $\mathrm{MCH}$ on standard chow is roughly of the same magnitude as OX [49]. Intake of chow is increased in rats and mice after injection of $\mathrm{MCH}$ into the lateral or third ventricles $[9,49,67]$, hypothalamic paraventricular nucleus [68], and NAc shell [69], while it is decreased after injection of an MCHR1 antagonist in the NAc shell [70] or periphery [71]. Although adult ppMCH and MCHR1 knockouts compared to wild-type mice actually demonstrate hyperphagia $[41,43,72]$, there is evidence that ppMCH knockouts at a young age consume significantly less chow $[41,42]$, indicating that $\mathrm{MCH}$ has some role in controlling intake of standard food.

Similar to OX, the orexigenic effect of $\mathrm{MCH}$ is more robust with palatable food, particularly with calorically dense food. ICV injection of $\mathrm{MCH}$ promotes the intake of a highor medium-fat diet, more than a chow diet $[45,73,74]$, and ICV or peripheral injection of an $\mathrm{MCH}$ antagonist decreases intake of and operant responding for these diets $[45,75,76]$. Further, transgenic ppMCH overexpressors compared to wild-type mice exhibit increased consumption of a high-fat diet [40]. A similar relationship for $\mathrm{MCH}$ is seen with sucrose, with ICV MCH stimulating intake of sucrose solutions [77-79] and systemic administration of the MCHR1 antagonist GW803430 decreasing sucrose selfadministration [80]. Notably, the relationship of $\mathrm{MCH}$ with palatable food does not extend to sweet, noncaloric saccharin $[79,80]$, indicating that $\mathrm{MCH}$ may be related more to energy conservation than to the intake of palatable food per se.

The ability of $\mathrm{MCH}$ to stimulate food intake may be due more to its reinforcement of ongoing intake rather than to an effect on the motivation to eat. This is supported by evidence showing that mice lacking the ppMCH gene show decreased responding for a high-fat diet under both fixed and progressive ratio schedules [81] and that Wistar rats given systemic injection of the MCHR1 antagonist GW803430 show reduced fixed and progressive ratio responding for a sucrose solution [80]. Further, although the same injection was found to suppress cue-induced reinstatement of lever pressing for sucrose [80], MCH blockade does not affect reinstatement for fat. Neither peripheral injection of the MCHR1 antagonist SNAP 94847 in rats nor chronic loss of ppMCH in mice significantly affects either cue- or pelletinduced reinstatement of fat seeking $[58,81]$. Together, this evidence indicates that $\mathrm{MCH}$ promotes food intake primarily by increasing energy conservation, motivating animals to continue consuming energy-dense foods.

4.2. Effects of Food Intake on Peptides. Another set of studies that tie $\mathrm{OX}$ and $\mathrm{MCH}$ to food intake examines the effects of various feeding conditions on their levels of mRNA or peptide.
4.2.1. Orexin. Neurons containing OX are activated in anticipation of feeding but also following consumption of food, provided that it is palatable food. Food deprivation upregulates gene expression and protein levels of OX (OX-A and $\mathrm{OX}-\mathrm{B}$ ) and both of its receptors in the hypothalamus [82] as early as twenty-four hours after onset. After a forty-eight hour fast, similar changes have been observed [6,83], and in female rats, the activity of OX neurons is also upregulated, as indicated by double-labeling of OX with phosphorylated CREB [84]. Given the relationship of OX with glucose (see Section 3.3), these changes after food deprivation may reflect lowered glucose levels; however, they may also reflect changes in arousal, as a single day of food deprivation increases wheel running activity [85] and decreases the total number of sleep episodes [86], effects that occur under conditions of heightened OX activity and are taken to indicate foraging behavior.

In line with the effects of food deprivation, OX neuronal activity and gene expression are also upregulated when animals are expecting to receive valued food. In rats with restricted access, OX mRNA and double-labeling of OX with c-Fos are elevated prior to access to a daily meal of chow, corn oil, or chocolate [57,87], while OX levels begin to return to baseline within 30 minutes after the start of meal consumption [87]. In sated rats, OX and c-Fos doublelabeling is also increased by a tone that signals the availability of palatable food in the form of high-sucrose pellets [88]. Siegel and colleagues [89] demonstrated that the expression of Fos in OX neurons increases in animals working for chow during the light phase but not when working to avoid shock or when receiving unearned rewards. These results suggest that OX neurons are activated in conditions when animals expect to receive specific, often preferred foods. In further support of this idea, c-Fos expression in OX neurons is also increased during extinction of sucrose seeking [61], when animals are motivated to obtain food rewards.

After consuming palatable food, OX levels are similarly elevated. With high-fat compared to low-fat, highcarbohydrate food, OX gene expression, and OX-A peptide levels are elevated after a single meal or up to three weeks on the diet [90-92], with longer periods of exposure leading to compensatory decreases in OX [93]. Interestingly, this fatinduced increase in OX may occur more from saturated than unsaturated fat, as consumption of a lard-based diet leads to higher OX mRNA levels than does that of a fish oil-based diet $[94,95]$. Similar to the results with fat, OX gene expression is also elevated following consumption of a high-sugar diet [96]. Together, these findings indicate that OX is activated both when animals are seeking food and also after they have consumed palatable food, which may in part explain why these foods are consumed in excess.

4.2.2. $\mathrm{MCH}$. Unlike neurons containing $\mathrm{OX}$, those containing $\mathrm{MCH}$ are not consistently activated in anticipation of feeding, although they are activated following consumption of a palatable, caloric food. Gene expression of $\mathrm{MCH}$ is upregulated after twenty-four hours of food deprivation $[9,97]$, although longer periods of fasting either increase peptide levels or leave them unchanged [97-99]. The failure 
to observe an increase may be due to the sensitivity of $\mathrm{MCH}$ neurons to the sleep-wake cycle. This is indicated by evidence showing $\mathrm{MCH}$ peptide levels after forty-eight hours of food deprivation to be increased in rats sacrificed during their resting (light) phase, but not their active (dark) stage [100] when MCH neurons are normally quiescent. Alternatively, $\mathrm{MCH}$ may play a less prominent role than OX in food seeking induced by deprivation, particularly as $\mathrm{MCH}$ neurons are excited by elevated glucose levels (see Section 3.3). Thus, these changes in $\mathrm{MCH}$ in response to food deprivation, unlike with OX, may be related more to changes in caloric efficiency than in circulating glucose.

In contrast to $\mathrm{OX}$, there is little evidence linking $\mathrm{MCH}$ with the expectation of receiving food, with double-labeling of c-Fos and $\mathrm{MCH}$ in sated rats unchanged by a tone signaling the availability of high-sucrose pellets [88].

Levels of $\mathrm{MCH}$ after consuming calorically rich food are clearly increased, supporting its role in palatable food consumption. With maintenance on a high-fat compared to low-fat diet, $\mathrm{MCH}$ gene expression and hypothalamic peptide levels as well as hypothalamic MCHR1 mRNA levels are elevated [101, 102]. Although the type of fat in the diet may not make a difference in this effect [95], the caloric content appears to be essential, with drinking of noncaloric saccharin having no effect on $\mathrm{MCH}$ gene expression [103]. Thus, consistent with its proposed role described previously in promoting motivation for intake of caloric food, these results indicate that $\mathrm{MCH}$ is activated after animals have consumed caloric food, further promoting overconsumption.

\section{Interactions with Other Neurochemicals}

Whereas $\mathrm{OX}$ and $\mathrm{MCH}$ each play a significant role in the consumption of palatable food, it is clear that these neuropeptides do not work in isolation. Two classes of neurochemicals with which they directly interact are first-order feeding neuropeptides of the arcuate nucleus and dopamine in the limbic system.

5.1. Arcuate Peptides. The orexigenic actions of $\mathrm{OX}$ and $\mathrm{MCH}$ may be due, in part, to their similar downstream activation of neuropeptides in the hypothalamic arcuate nucleus, NPY and agouti-related protein (AgRP). In the arcuate, OX-positive axon terminals directly contact neurons containing NPY [104], and OX1R protein is located on both NPY and AgRPcontaining neurons [21]. Orexin also directly activates NPY neurons, as the addition of OX-A or OX-B to the superfusate of isolated arcuate NPY neurons increases their intracellular calcium content [104]. This translates into effects of OX on feeding, as the orexigenic effect of ICV OX-A or OX-B is greatly reduced by ICV pretreatment with an NPY receptor antagonist $[105,106]$. Similarly, chronic ICV injection with $\mathrm{MCH}$, which stimulates feeding, also upregulates NPY gene expression [107], and the orexigenic effect of ICV MCH is significantly diminished by ICV injection of an NPY receptor antagonist [108]. In part then, the similar ability of OX and $\mathrm{MCH}$ to promote food intake may be due to their similar downstream effects on other orexigenic neuropeptides.
5.2. Limbic Dopamine. The dissimilar motivation and arousal-related actions of $\mathrm{OX}$ and $\mathrm{MCH}$ may be due more to their opposing downstream effects on the neurotransmitter dopamine (DA), in limbic nuclei such as the NAc and prefrontal cortex (PFC). A rise in OX levels results in DA release into the NAc shell and PFC, which can occur from OX acting directly at DA terminals or at their source in the VTA. Application of OX-A to PFC slices increases phasically evoked DA release, an effect inhibited by the OX1R antagonist SB334867 [109], and application of OX-A or OX-B to VTA slices increases the firing frequency of DA neurons [110]. Similarly, ICV injection of OX-A stimulates c-Fos in VTA DA neurons, primarily in those projecting to the NAc shell and PFC rather than the NAc core [111]. In line with this, ICV OX-A is also found to elevate levels of DA in the PFC but not the NAc core [112]. These findings with OX contrast with those observed with $\mathrm{MCH}$, which through transgenic studies appears to inhibit accumbal DA. Mice lacking ppMCH exhibit increased electrically evoked DA release in the NAc shell and increased DA transporter levels in both the NAc shell and core $[81,113]$. As the application of $\mathrm{MCH}$ to VTA slices fails to affect firing of DA neurons [110], these DA changes in knockout mice may be due to presynaptic actions in the NAc. These opposite effects of OX and $\mathrm{MCH}$ on limbic DA may help to explain their opposite effects on arousal and reward (see Section 6).

It is interesting to consider the similar orexigenic actions of $\mathrm{OX}$ and $\mathrm{MCH}$ in light of their opposite effects on DA. This neurotransmitter plays an important role in promoting foodseeking behavior [114] and appetitive motivational processes in general [115], but animals will also work to enhance DA levels when they are low [116]. In fact, animals prone to overeating a high-fat diet exhibit markedly reduced basal levels of DA in the NAc [117]. Seemingly then, palatable food intake can be increased from an OX-induced elevation of DA, which increases arousal and seeking of palatable food $[118,119]$, but it can also be increased by an $\mathrm{MCH}$-induced reduction in DA, which produces anhedonia (see Section 6.2) and the need to restore DA levels through the consumption of palatable food [117]. This suggests the possibility that OX may contribute to the rise in accumbal DA that normally occurs prior to meal consumption, while $\mathrm{MCH}$ may contribute to the fall observed during the feeding bout [120].

\section{Role in Reward}

In line with their opposite effects on limbic DA, OX and $\mathrm{MCH}$ largely have opposite effects on processes of reward. Whereas OX increases the reinforcing properties of ingested substances, $\mathrm{MCH}$ instead appears to promote depression and anxiety.

6.1. Orexin. The peptide OX plays a role in reward and reinforcement, acting through OX1R or OX2R. In tests of conditioned place preference (CPP) following pairing with drug administration, VTA injection of OX-A during conditioning induces morphine CPP in a dose-dependent manner [121], and peripheral administration of the OX1R antagonist 
SB-334867 or OX2R antagonist TCS-OX2-29 suppresses its acquisition and expression [122, 123]. While morphine CPP may be perpetuated by OX binding at OX1R or OX2R, ethanol CPP appears to be mediated more by OX2R. Acquisition, expression, and reinstatement of ethanol CPP are attenuated by peripheral treatment with the OX2R antagonist JNJ10397049 but not by the OX1R antagonists SB-408124 [124] or SB-334867 [125]. The reinforcing effects of naturally rewarding stimuli may also involve OX. In male rats, conditioned cues associated with sexual behavior in a CPP paradigm induce c-Fos in OX neurons, and lesioning of OX neurons prevents the formation of CPP for a chamber paired with sexual behavior [126]. Thus, OX may be important in reward processing of both drugs of abuse and also natural rewards, such as sexual activity or palatable food intake.

6.2. $\mathrm{MCH}$. In contrast to $\mathrm{OX}, \mathrm{MCH}$ may not promote reward processing but instead is linked with anxiety and depression. Mice with deletions of MCHR1 show no difference from their wild-type counterparts in cocaine- or amphetamine-induced CPP [127] and in fact show hypersensitivity to the locomotor activating effects of the DA psychostimulant d-amphetamine [128], suggesting that these mice have enhanced druginduced reward processing. Instead, $\mathrm{MCH}$ is strongly linked with anhedonia in the forced swim test (FST). The amount of time spent immobile in the FST correlates positively with ppMCH mRNA [129], and MCHR1 antagonists produce an antidepressant effect in the FST when administered peripherally [130] or directly in the NAc shell [70, 131]. Conversely, NAc shell injection of MCH produces the opposite effect [70]. The MCHR1 antagonist SNAP-7941 also acts as anxiolytic in tests of rat social interaction and guinea pig maternalseparation vocalization [130]. Thus, in contrast to $\mathrm{OX}, \mathrm{MCH}$ may in some cases act as an antireward neuropeptide.

\section{Conclusions}

In summary, $\mathrm{OX}$ and $\mathrm{MCH}$, expressed in the $\mathrm{LH}$ and acting through their receptors in many of the same nuclei of the brain, are similar both in promoting the consumption of palatable or caloric food and in being stimulated by the intake of this food, responding in a positive feedback cycle to promote excess consumption. Importantly, they appear to have complementary roles in controlling this feeding behavior, likely through their largely opposite roles in reward systems and motivation, as well as a number of physiological processes, including the sleep-wake cycle, energy expenditure, and glucose metabolism. Perhaps for these reasons, OX and $\mathrm{MCH}$ affect different aspects of food intake. The evidence suggests that OX is activated in situations of food seeking and promotes the motivation for food reward, possibly activating the feeding process, whereas $\mathrm{MCH}$ plays a larger role during ongoing food intake and reinforces consumption, acting to prolong the intake of energy-dense foods. Thus, for a single meal, OX may be involved in initiating palatable food intake and activating $\mathrm{MCH}$ neurons, and after meal initiation and the consequent rise in glucose, $\mathrm{MCH}$ functions to prolong the consumption of calories for the sake of energy conservation.
These physiological and behavioral effects of $\mathrm{OX}$ and $\mathrm{MCH}$ can be further understood in light of their downstream effects on other neurochemicals. While these neuropeptides both upregulate NPY which may contribute to their similar orexigenic effects, they have opposite effects on limbic DA, which may contribute to their complementary effects on reward and motivation that themselves can enhance palatable food intake. These two peptides in the $\mathrm{LH}$ provide an interesting example of the complex and sometimes opposing physiological, behavioral, and neurochemical processes that are involved in promoting the ingestion of palatable food.

\section{Conflict of Interests}

The authors declare no conflict of interests.

\section{Acknowledgments}

This research was supported by the National Institute on Alcohol Abuse and Alcoholism of the National Institutes of Health under Award nos. K99AA021782 (JRB) and R01AA12882 (SFL). The content is solely the responsibility of the authors and does not necessarily represent the official views of the NIH.

\section{References}

[1] B. K. Anand and J. R. Brobeck, "Localization of a "feeding center" in the hypothalamus of the rat," Proceedings of the Society for Experimental Biology and Medicine, vol. 77, no. 2, pp. 323-324, 1951.

[2] J. M. Delgado and B. K. Anand, "Increase of food intake induced by electrical stimulation of the lateral hypothalamus," The American Journal of Physiology, vol. 172, no. 1, pp. 162-168, 1953.

[3] B. G. Hoebel and P. Teitelbaum, "Hypothalamic control of feeding and self-stimulation," Science, vol. 135, no. 3501, pp. 375377, 1962.

[4] D. de Wied, "Neuropeptides and behavior," The Nederlands Tijdschrift voor Geneeskunde, vol. 118, no. 49, pp. 1865-1869, 1974.

[5] L. de Lecea, T. S. Kilduff, C. Peyron et al., "The hypocretins: hypothalamus-specific peptides with neuroexcitatory activity," Proceedings of the National Academy of Sciences of the United States of America, vol. 95, no. 1, pp. 322-327, 1998.

[6] T. Sakurai, A. Amemiya, M. Ishii et al., "Orexins and orexin receptors: a family of hypothalamic neuropeptides and $G$ protein-coupled receptors that regulate feeding behavior," Cell, vol. 92, no. 4, pp. 573-585, 1998.

[7] M. Modirrousta, L. Mainville, and B. E. Jones, "Orexin and $\mathrm{MCH}$ neurons express c-Fos differently after sleep deprivation versus recovery and bear different adrenergic receptors," European Journal of Neuroscience, vol. 21, no. 10, pp. 2807-2816, 2005.

[8] H. Kawauchi, I. Kawazoe, M. Tsubokawa, M. Kishida, and B. I. Baker, "Characterization of melaninconcentrating hormone in chum salmon pituitaries," Nature, vol. 305, no. 5932, pp. 321-323, 1983.

[9] D. Qu, D. S. Ludwig, S. Gammeltoft et al., "A role for melaninconcentrating hormone in the central regulation of feeding behaviour," Nature, vol. 380, no. 6571, pp. 243-247, 1996. 
[10] G. Skofitsch, D. M. Jacobowitz, and N. Zamir, "Immunohistochemical localization of a melanin concentrating hormone-like peptide in the rat brain," Brain Research Bulletin, vol. 15, no. 6, pp. 635-649, 1985.

[11] A. N. van den Pol, X. Gao, K. Obrietan, T. S. Kilduff, and A. B. Belousov, "Presynaptic and postsynaptic actions and modulation of neuroendocrine neurons by a new hypothalamic peptide, hypocretin/orexin," Journal of Neuroscience, vol. 18, no. 19, pp. 7962-7971, 1998.

[12] C. P. Tan, H. Sano, H. Iwaasa et al., "Melanin-concentrating hormone receptor subtypes 1 and 2: species-specific gene expression," Genomics, vol. 79, no. 6, pp. 785-792, 2002.

[13] B. E. Hawes, K. I. L. Erin, B. Green, K. I. M. O’Neill, S. Fried, and M. P. Graziano, "The melanin-concentrating hormone receptor couples to multiple $\mathrm{G}$ proteins to activate diverse intracellular signaling pathways," Endocrinology, vol. 141, no. 12, pp. 45244532,2000

[14] J. Chambers, R. S. Ames, D. Bergsma et al., "Melanin-concentrating hormone is the cognate ligand for the orphan Gprotein-coupled receptor SLC-1," Nature, vol. 400, no. 6741, pp. 261-265, 1999.

[15] P. M. C. Lembo, E. Grazzini, J. Cao et al., "The receptor for the orexigenic peptide melanin-concentrating hormone is a Gprotein-coupled receptor," Nature Cell Biology, vol. 1, no. 5, pp. 267-271, 1999.

[16] J. C. Bittencourt, F. Presse, C. Arias et al., "The melaninconcentrating hormone system of the rat brain: an immunoand hybridization histochemical characterization," Journal of Comparative Neurology, vol. 319, no. 2, pp. 218-245, 1992.

[17] C. Peyron, D. K. Tighe, A. N. van den Pol et al., "Neurons containing hypocretin (orexin) project to multiple neuronal systems," Journal of Neuroscience, vol. 18, no. 23, pp. 9996-10015, 1998.

[18] J. N. Marcus, C. J. Aschkenasi, C. E. Lee et al., "Differential expression of orexin receptors 1 and 2 in the rat brain," Journal of Comparative Neurology, vol. 435, no. 1, pp. 6-25, 2001.

[19] Y. Saito, M. Cheng, F. M. Leslie, and O. Civelli, "Expression of the melanin-concentrating hormone $(\mathrm{MCH})$ receptor mRNA in the rat brain," Journal of Comparative Neurology, vol. 435, no. 1 , pp. 26-40, 2001.

[20] J.-L. Guan, K. Uehara, S. Lu et al., "Reciprocal synaptic relationships between orexin- and melanin-concentrating hormonecontaining neurons in the rat lateral hypothalamus: a novel circuit implicated in feeding regulation," International Journal of Obesity, vol. 26, no. 12, pp. 1523-1532, 2002.

[21] M. Bäckberg, G. Hervieu, S. Wilson, and B. Meister, "Orexin receptor-1 (OX-R1) immunoreactivity in chemically identified neurons of the hypothalamus: focus on orexin targets involved in control of food and water intake," European Journal of Neuroscience, vol. 15, no. 2, pp. 315-328, 2002.

[22] A. N. van den Pol, C. Acuna-Goycolea, K. R. Clark, and P. K. Ghosh, "Physiological properties of hypothalamic $\mathrm{MCH}$ neurons identified with selective expression of reporter gene after recombinant virus infection," Neuron, vol. 42, no. 4, pp. 635-652, 2004.

[23] Y. Rao, M. Lu, F. Ge et al., "Regulation of synaptic efficacy in hypocretin/orexin-containing neurons by melanin concentrating hormone in the lateral hypothalamus," Journal of Neuroscience, vol. 28, no. 37, pp. 9101-9110, 2008.

[24] M. G. Lee, O. K. Hassani, and B. E. Jones, "Discharge of identified orexin/hypocretin neurons across the sleep-waking cycle," Journal of Neuroscience, vol. 25, no. 28, pp. 6716-6720, 2005.

[25] K. Takahashi, J. S. Lin, and K. Sakai, "Neuronal activity of orexin and non-orexin waking-active neurons during wakesleep states in the mouse," Neuroscience, vol. 153, no. 3, pp. 860870, 2008.

[26] B. Y. Mileykovskiy, L. I. Kiyashchenko, and J. M. Siegel, "Behavioral correlates of activity in identified hypocretin/orexin neurons," Neuron, vol. 46, no. 5, pp. 787-798, 2005.

[27] R. A. Espaa, B. A. Baldo, A. E. Kelley, and C. W. Berridge, "Wake-promoting and sleep-suppressing actions of hypocretin (orexin): basal forebrain sites of action," Neuroscience, vol. 106, no. 4, pp. 699-715, 2001.

[28] C. Dugovic, J. E. Shelton, L. E. Aluisio et al., "Blockade of orexin-1 receptors attenuates orexin-2 receptor antagonisminduced sleep promotion in the rat," Journal of Pharmacology and Experimental Therapeutics, vol. 330, no. 1, pp. 142-151, 2009.

[29] R. M. Chemelli, J. T. Willie, C. M. Sinton et al., "Narcolepsy in orexin knockout mice: molecular genetics of sleep regulation," Cell, vol. 98, no. 4, pp. 437-451, 1999.

[30] L. Lin, J. Faraco, R. Li et al., “The sleep disorder canine narcolepsy is caused by a mutation in the hypocretin (orexin) receptor 2 gene," Cell, vol. 98, no. 3, pp. 365-376, 1999.

[31] T. C. Thannickal, R. Y. Moore, R. Nienhuis et al., "Reduced number of hypocretin neurons in human narcolepsy," Neuron, vol. 27, no. 3, pp. 469-474, 2000.

[32] O. K. Hassani, M. G. Lee, and B. E. Jones, "Melanin-concentrating hormone neurons discharge in a reciprocal manner to orexin neurons across the sleep-wake cycle," Proceedings of the National Academy of Sciences of the United States of America, vol. 106, no. 7, pp. 2418-2422, 2009.

[33] L. Verret, R. Goutagny, P. Fort et al., "A role of melanin-concentrating hormone producing neurons in the central regulation of paradoxical sleep," BMC Neuroscience, vol. 4, article 19, 2003.

[34] A. Ahnaou, F. M. Dautzenberg, H. Huysmans, T. Steckler, and W. H. I. M. Drinkenburg, "Contribution of melaninconcentrating hormone (MCH1) receptor to thermoregulation and sleep stabilization: evidence from MCH1 (-/-) mice," Behavioural Brain Research, vol. 218, no. 1, pp. 42-50, 2011.

[35] J. T. Willie, C. M. Sinton, E. Maratos-Flier, and M. Yanagisawa, "Abnormal response of melanin-concentrating hormone deficient mice to fasting: hyperactivity and rapid eye movement sleep suppression," Neuroscience, vol. 156, no. 4, pp. 819-829, 2008.

[36] T. C. Thannickal, R. Nienhuis, and J. M. Siegel, "Localized loss of hypocretin (orexin) cells in narcolepsy without cataplexy," Sleep, vol. 32, no. 8, pp. 993-998, 2009.

[37] H. Funato, A. L. Tsai, J. T. Willie et al., "Enhanced orexin receptor-2 signaling prevents diet-induced obesity and improves leptin sensitivity," Cell Metabolism, vol. 9, no. 1, pp. 64-76, 2009.

[38] A. Asakawa, A. Inui, K. Goto et al., "Effects of agouti-related protein, orexin and melanin-concentrating hormone on oxygen consumption in mice," International Journal of Molecular Medicine, vol. 10, no. 4, pp. 523-525, 2002.

[39] N. M. Semjonous, K. L. Smith, J. R. C. Parkinson et al., "Coordinated changes in energy intake and expenditure following hypothalamic administration of neuropeptides involved in energy balance," International Journal of Obesity, vol. 33, no. 7, pp. 775-785, 2009. 
[40] D. S. Ludwig, N. A. Tritos, J. W. Mastaitis et al., "Melaninconcentrating hormone overexpression in transgenic mice leads to obesity and insulin resistance," Journal of Clinical Investigation, vol. 107, no. 3, pp. 379-386, 2001.

[41] J. D. Mul, C. X. Yi, S. A. A. van den Berg et al., "Pmch expression during early development is critical for normal energy homeostasis," The American Journal of Physiology, vol. 298, no. 3, pp. E477-E488, 2010.

[42] M. Shimada, N. A. Tritos, B. B. Lowell, J. S. Flier, and E. Maratos-Flier, "Mice lacking melanin-concentrating hormone are hypophagic and lean," Nature, vol. 396, no. 6712, pp. 670674, 1998.

[43] D. J. Marsh, D. T. Weingarth, D. E. Novi et al., "Melanin-concentrating hormone 1 receptor-deficient mice are lean, hyperactive, and hyperphagic and have altered metabolism," Proceedings of the National Academy of Sciences of the United States of America, vol. 99, no. 5, pp. 3240-3245, 2002.

[44] M. S. Mondal, M. Nakazato, and S. Matsukura, "Characterization of orexins (hypocretins) and melanin-concentrating hormone in genetically obese mice," Regulatory Peptides, vol. 104, no. 1-3, pp. 21-25, 2002.

[45] L. P. Shearman, R. E. Camacho, D. S. Stribling et al., "Chronic $\mathrm{MCH}-1$ receptor modulation alters appetite, body weight and adiposity in rats," European Journal of Pharmacology, vol. 475, no. 1-3, pp. 37-47, 2003.

[46] D. Burdakov, O. Gerasimenko, and A. Verkhratsky, "Physiological changes in glucose differentially modulate the excitability of hypothalamic melanin-concentrating hormone and orexin neurons in situ," Journal of Neuroscience, vol. 25, no. 9, pp. 24292433, 2005.

[47] D. Burdakov, L. T. Jensen, H. Alexopoulos et al., "Tandem-pore $\mathrm{K}^{+}$channels mediate inhibition of orexin neurons by glucose," Neuron, vol. 50, no. 5, pp. 711-722, 2006.

[48] D. Kong, L. Vong, L. E. Parton et al., "Glucose stimulation of hypothalamic MCH neurons involves KATP channels, is modulated by ucp2, and regulates peripheral glucose homeostasis," Cell Metabolism, vol. 12, no. 5, pp. 545-552, 2010.

[49] C. M. B. Edwards, S. Abusnana, D. Sunter, K. G. Murphy, M. A. Ghatei, and S. R. Bloom, "The effect of the orexins on food intake: comparison with neuropeptide $\mathrm{Y}$, melaninconcentrating hormone and galanin," Journal of Endocrinology, vol. 160, no. 3, pp. R7-R12, 1999.

[50] Y. Zhu, A. Yamanaka, K. Kunii, N. Tsujino, K. Goto, and T. Sakurai, "Orexin-mediated feeding behavior involves both leptinsensitive and -insensitive pathways," Physiology and Behavior, vol. 77, no. 2-3, pp. 251-257, 2002.

[51] M. G. Dube, S. P. Kalra, and P. S. Kalra, "Food intake elicited by central administration of orexins/hypocretins: identification of hypothalamic sites of action," Brain Research, vol. 842, no. 2, pp. 473-477, 1999.

[52] D. C. Sweet, A. S. Levine, C. J. Billington, and C. M. Kotz, "Feeding response to central orexins," Brain Research, vol. 821, no. 2, pp. 535-538, 1999.

[53] E. R. Schneider, P. Rada, R. D. Darby, S. F. Leibowitz, and B. G. Hoebel, "Orexigenic peptides and alcohol intake: differential effects of orexin, galanin, and ghrelin," Alcoholism: Clinical and Experimental Research, vol. 31, no. 11, pp. 1858-1865, 2007.

[54] A. J. Thorpe and C. M. Kotz, "Orexin A in the nucleus accumbens stimulates feeding and locomotor activity," Brain Research, vol. 1050, no. 1-2, pp. 156-162, 2005.
[55] S. Kaur, S. Thankachan, S. Begum et al., "Entrainment of temperature and activity rhythms to restricted feeding in orexin knock out mice," Brain Research, vol. 1205, pp. 47-54, 2008.

[56] R. Sharf, M. Sarhan, C. E. Brayton, D. J. Guarnieri, J. R. Taylor, and R. J. DiLeone, "Orexin signaling via the orexin 1 receptor mediates operant responding for food reinforcement," Biological Psychiatry, vol. 67, no. 8, pp. 753-760, 2010.

[57] D. L. Choi, J. F. Davis, M. E. Fitzgerald, and S. C. Benoit, "The role of orexin-A in food motivation, reward-based feeding behavior and food-induced neuronal activation in rats," Neuroscience, vol. 167, no. 1, pp. 11-20, 2010.

[58] S. G. Nair, S. A. Golden, and Y. Shaham, "Differential effects of the hypocretin 1 receptor antagonist SB 334867 on high-fat food self-administration and reinstatement of food seeking in rats," The British Journal of Pharmacology, vol. 154, no. 2, pp. 406-416, 2008.

[59] C. L. White, Y. Ishii, T. Mendoza et al., "Effect of a selective OX1R antagonist on food intake and body weight in two strains of rats that differ in susceptibility to dietary-induced obesity," Peptides, vol. 26, no. 11, pp. 2331-2338, 2005.

[60] D. J. Clegg, E. L. Air, S. C. Woods, and R. J. Seeley, "Eating elicited by orexin-A, but not melanin-concentrating hormone, is opioid mediated," Endocrinology, vol. 143, no. 8, pp. 29953000, 2002.

[61] A. M. Cason and G. Aston-Jones, "Role of orexin/hypocretin in conditioned sucrose-seeking in rats," Psychopharmacology, vol. 226, no. 1, pp. 155-165, 2013.

[62] B. Jupp, B. Krivdic, E. Krstew, and A. J. Lawrence, "The orexin1 receptor antagonist SB-334867 dissociates the motivational properties of alcohol and sucrose in rats," Brain Research, vol. 1391, pp. 54-59, 2011.

[63] J. K. Richards, J. A. Simms, P. Steensland et al., "Inhibition of orexin-1/hypocretin-1 receptors inhibits yohimbine-induced reinstatement of ethanol and sucrose seeking in Long-Evans rats," Psychopharmacology, vol. 199, no. 1, pp. 109-117, 2008.

[64] E. Matsuo, A. Mochizuki, K. Nakayama et al., "Decreased intake of sucrose solutions in orexin knockout mice," Journal of Molecular Neuroscience, vol. 43, no. 2, pp. 217-224, 2011.

[65] L. Piccoli, M. V. M. Di Bonaventura, C. Cifani et al., "Role of orexin-1 receptor mechanisms on compulsive food consumption in a model of binge eating in female rats," Neuropsychopharmacology, vol. 37, no. 9, pp. 1999-2011, 2012.

[66] M. Akiyama, T. Yuasa, N. Hayasaka, K. Horikawa, T. Sakurai, and S. Shibata, "Reduced food anticipatory activity in genetically orexin (hypocretin) neuron-ablated mice," European Journal of Neuroscience, vol. 20, no. 11, pp. 3054-3062, 2004.

[67] M. Rossi, S. J. Choi, D. O’Shea, T. Miyoshi, M. A. Ghatei, and S. R. Bloom, "Melanin-concentrating hormone acutely stimulates feeding, but chronic administration has no effect on body weight," Endocrinology, vol. 138, no. 1, pp. 351-355, 1997.

[68] M. Rossi, S. A. Beak, S. J. Choi et al., "Investigation of the feeding effects of melanin concentrating hormone on food intakeaction independent of galanin and the melanocortin receptors," Brain Research, vol. 846, no. 2, pp. 164-170, 1999.

[69] B. Guesdon, E. Paradis, P. Samson, and D. Richard, "Effects of intracerebroventricular and intra-accumbens melaninconcentrating hormone agonism on food intake and energy expenditure," The American Journal of Physiology, vol. 296, no. 3, pp. R469-R475, 2009.

[70] D. Georgescu, R. M. Sears, J. D. Hommel et al., “The hypothalamic neuropeptide melanin-concentrating hormone acts in the nucleus accumbens to modulate feeding behavior and forcedswim performance," Journal of Neuroscience, vol. 25, no. 11, pp. 2933-2940, 2005. 
[71] O. Della-Zuana, V. Audinot, V. Levenez et al., "Peripheral injections of melanin-concentrating hormone receptor 1 antagonist S38151 decrease food intake and body weight in rodent obesity models," Frontiers in Endocrinology, vol. 3, article 160, 2012.

[72] E. Kokkotou, J. Y. Jeon, X. Wang et al., "Mice with $\mathrm{MCH}$ ablation resist diet-induced obesity through strain-specific mechanisms," The American Journal of Physiology, vol. 289, no. 1, pp. R117-R124, 2005.

[73] A. Gomori, A. Ishihara, M. Ito et al., "Chronic intracerebroventricular infusion of $\mathrm{MCH}$ causes obesity in mice," The American Journal of Physiology, vol. 284, no. 3, pp. E583-E588, 2003.

[74] M. Ito, A. Gomori, A. Ishihara et al., "Characterization of MCHmediated obesity in mice," The American Journal of Physiology, vol. 284, no. 5, pp. E940-E945, 2003.

[75] S. Mashiko, A. Ishihara, A. Gomori et al., "Antiobesity effect of a melanin-concentrating hormone 1 receptor antagonist in dietinduced obese mice," Endocrinology, vol. 146, no. 7, pp. 30803086, 2005.

[76] S. G. Nair, T. Adams-Deutsch, C. L. Pickens, D. G. Smith, and Y. Shaham, "Effects of the MCH1 receptor antagonist SNAP 94847 on high-fat food-reinforced operant responding and reinstatement of food seeking in rats," Psychopharmacology, vol. 205, no. 1, pp. 129-140, 2009.

[77] J. P. Baird, C. Rios, N. E. Gray, C. E. Walsh, S. G. Fischer, and A. L. Pecora, "Effects of melanin-concentrating hormone on licking microstructure and brief-access taste responses," The American Journal of Physiology, vol. 291, no. 5, pp. R1265-R1274, 2006.

[78] E. A. Duncan, K. Proulx, and S. C. Woods, "Central administration of melanin-concentrating hormone increases alcohol and sucrose/quinine intake in rats," Alcoholism: Clinical and Experimental Research, vol. 29, no. 6, pp. 958-964, 2005.

[79] R. Sakamaki, M. Uemoto, A. Inui et al., "Melanin-concentrating hormone enhances sucrose intake," International Journal of Molecular Medicine, vol. 15, no. 6, pp. 1033-1039, 2005.

[80] C. Karlsson, M. Zook, R. Ciccocioppo et al., "Melanin-concentrating hormone receptor 1 (MCH1-R) antagonism: reduced appetite for calories and suppression of addictive-like behaviors," Pharmacology Biochemistry and Behavior, vol. 102, no. 3, pp. 400-406, 2012.

[81] J. D. Mul, S. E. la Fleur, P. W. Toonen et al., "Chronic loss of melanin-concentrating hormone affects motivational aspects of feeding in the rat," PLoS ONE, vol. 6, no. 5, Article ID e19600, 2011.

[82] E. Karteris, R. J. Machado, J. Chen, S. Zervou, E. W. Hillhouse, and H. S. Randeva, "Food deprivation differentially modulates orexin receptor expression and signaling in rat hypothalamus and adrenal cortex," The American Journal of Physiology, vol. 288, no. 6, pp. E1089-E1100, 2005.

[83] X. J. Cai, P. S. Widdowson, J. Harrold et al., "Hypothalamic orexin expression: modulation by blood glucose and feeding," Diabetes, vol. 48, no. 11, pp. 2132-2137, 1999.

[84] T. Funabashi, H. Hagiwara, K. Mogi, D. Mitsushima, K. Shinohara, and F. Kimura, "Sex differences in the responses of orexin neurons in the lateral hypothalamic area and feeding behavior to fasting," Neuroscience Letters, vol. 463, no. 1, pp. 31-34, 2009.

[85] F. W. Finger, "Effect of food deprivation on running-wheel activity in naive rats," Psychological Reports, vol. 16, pp. 753-757, 1965.

[86] A. A. Borbely, "Sleep in the rat during food deprivation and subsequent restitution of food," Brain Research, vol. 124, no. 3, pp. 457-471, 1977.
[87] T. Mizushige, T. Kawai, S. Matsumura et al., "POMC and orexin mRNA expressions induced by anticipation of a cornoil emulsion feeding are maintained at the high levels until oil ingestion," Biomedical Research, vol. 27, no. 5, pp. 227-232, 2006.

[88] G. D. Petrovich, M. P. Hobin, and C. J. Reppucci, "Selective Fos induction in hypothalamic orexin/hypocretin, but not melaninconcentrating hormone neurons, by a learned food-cue that stimulates feeding in sated rats," Neuroscience, vol. 224, pp. 7080, 2012.

[89] R. McGregor, M. F. Wu, G. Barber, L. Ramanathan, and J. M. Siegel, "Highly specific role of hypocretin (orexin) neurons: differential activation as a function of diurnal phase, operant reinforcement versus operant avoidance and light level," Journal of Neuroscience, vol. 31, no. 43, pp. 15455-15467, 2011.

[90] V. A. Gaysinskaya, O. Karatayev, G. Q. Chang, and S. F. Leibowitz, "Increased caloric intake after a high-fat preload: relation to circulating triglycerides and orexigenic peptides," Physiology and Behavior, vol. 91, no. 1, pp. 142-153, 2007.

[91] E. S. Park, S. J. Yi, J. S. Kim et al., "Changes in orexin-A and neuropeptide $\mathrm{Y}$ expression in the hypothalamus of the fasted and high-fat diet fed rats," Journal of Veterinary Science, vol. 5, no. 4, pp. 295-302, 2004.

[92] K. E. Wortley, G. Q. Chang, Z. Davydova, and S. F. Leibowitz, "Orexin gene expression is increased during states of hypertriglyceridemia," The American Journal of Physiology, vol. 284, no. 6, pp. R1454-R1465, 2003.

[93] C. M. Novak, C. Escande, P. R. Burghardt et al., "Spontaneous activity, economy of activity, and resistance to diet-induced obesity in rats bred for high intrinsic aerobic capacity," Hormones and Behavior, vol. 58, no. 3, pp. 355-367, 2010.

[94] J. R. Barson, O. Karatayev, V. Gaysinskaya, G. Chang, and S. F. Leibowitz, "Effect of dietary fatty acid composition on food intake, triglycerides, and hypothalamic peptides," Regulatory Peptides, vol. 173, no. 1-3, pp. 13-20, 2012.

[95] B. Dziedzic, J. Szemraj, J. Bartkowiak, and A. Walczewska, "Various dietary fats differentially change the gene expression of neuropeptides involved in body weight regulation in rats," Journal of Neuroendocrinology, vol. 19, no. 5, pp. 364-373, 2007.

[96] P. K. Olszewski, T. J. Shaw, M. K. Grace et al., "Complexity of neural mechanisms underlying overconsumption of sugar in scheduled feeding: involvement of opioids, orexin, oxytocin and NPY," Peptides, vol. 30, no. 2, pp. 226-233, 2009.

[97] C. Hervé and D. Fellmann, "Changes in rat melanin-concentrating hormone and dynorphin messenger ribonucleic acids induced by food deprivation," Neuropeptides, vol. 31, no. 3, pp. 237-242, 1997.

[98] F. Bertile, H. Oudart, F. Criscuolo, Y. L. Maho, and T. Raclot, "Hypothalamic gene expression in long-term fasted rats: relationship with body fat," Biochemical and Biophysical Research Communications, vol. 303, no. 4, pp. 1106-1113, 2003.

[99] N. A. Tritos, J. W. Mastaitis, E. Kokkotou, and E. MaratosFlier, "Characterization of melanin concentrating hormone and preproorexin expression in the murine hypothalamus," Brain Research, vol. 895, no. 1-2, pp. 160-166, 2001.

[100] L. F. Harthoorn, A. Sañé, M. Nethe, and J. J. van Heerikhuize, "Multi-transcriptional profiling of melanin-concentrating hormone and orexin-containing neurons," Cellular and Molecular Neurobiology, vol. 25, no. 8, pp. 1209-1223, 2005.

[101] J. C. Elliott, J. A. Harrold, P. Brodin et al., "Increases in melanin-concentrating hormone and $\mathrm{MCH}$ receptor levels in the hypothalamus of dietary-obese rats," Molecular Brain Research, vol. 128, no. 2, pp. 150-159, 2004. 
[102] A. R. Kennedy, P. Pissios, H. Otu et al., "A high-fat, ketogenic diet induces a unique metabolic state in mice," The American Journal of Physiology, vol. 292, no. 6, pp. E1724-E1739, 2007.

[103] Y. Furudono, C. Ando, C. Yamamoto, M. Kobashi, and T. Yamamoto, "Involvement of specific orexigenic neuropeptides in sweetener-induced overconsumption in rats," Behavioural Brain Research, vol. 175, no. 2, pp. 241-248, 2006.

[104] S. Muroya, H. Funahashi, A. Yamanaka et al., "Orexins (hypocretins) directly interact with neuropeptide Y, POMC and glucose-responsive neurons to regulate $\mathrm{Ca}^{2+}$ signaling in a reciprocal manner to leptin: orexigenic neuronal pathways in the mediobasal hypothalamus," European Journal of Neuroscience, vol. 19, no. 6, pp. 1524-1534, 2004.

[105] M. G. Dube, T. L. Horvath, P. S. Kalra, and S. P. Kalra, "Evidence of NPY Y5 receptor involvement in food intake elicited by orexin A in sated rats," Peptides, vol. 21, no. 10, pp. 1557-1560, 2000.

[106] M. R. Jain, T. L. Horvath, P. S. Kalra, and S. P. Kalra, "Evidence that NPY Y1 receptors are involved in stimulation of feeding by orexins (hypocretins) in sated rats," Regulatory Peptides, vol. 87, no. 1-3, pp. 19-24, 2000.

[107] O. Della-Zuana, F. Presse, C. Ortola, J. Duhault, J. L. Nahon, and N. Levens, "Acute and chronic administration of melaninconcentrating hormone enhances food intake and body weight in Wistar and Sprague-Dawley rats," International Journal of Obesity, vol. 26, no. 10, pp. 1289-1295, 2002.

[108] C. L. Chaffer and M. J. Morris, "The feeding response to melanin-concentrating hormone is attenuated by antagonism of the NPY Y1-receptor in the rat," Endocrinology, vol. 143, no. 1, pp. 191-197, 2002.

[109] R. Patyal, E. Y. Woo, and S. L. Borgland, "Local hypocretin1 modulates terminal dopamine concentration in the nucleus accumbens shell," Frontiers in Behavioral Neuroscience, vol. 6, article 82, 2012.

[110] T. M. Korotkova, O. A. Sergeeva, K. S. Eriksson, H. L. Haas, and R. E. Brown, "Excitation of ventral tegmental area dopaminergic and nondopaminergic neurons by orexins/hypocretins," Journal of Neuroscience, vol. 23, no. 1, pp. 7-11, 2003.

[111] N. M. Vittoz, B. Schmeichel, and C. W. Berridge, "Hypocretin/orexin preferentially activates caudomedial ventral tegmental area dopamine neurons," European Journal of Neuroscience, vol. 28, no. 8, pp. 1629-1640, 2008.

[112] N. M. Vittoz and C. W. Berridge, "Hypocretin/orexin selectively increases dopamine efflux within the prefrontal cortex: involvement of the ventral tegmental area," Neuropsychopharmacology, vol. 31, no. 2, pp. 384-395, 2006.

[113] P. Pissios, L. Frank, A. R. Kennedy et al., "Dysregulation of the mesolimbic dopamine system and reward in $\mathrm{MCH}-/-$ mice," Biological Psychiatry, vol. 64, no. 3, pp. 184-191, 2008.

[114] R. A. Wise, "Role of brain dopamine in food reward and reinforcement," Philosophical Transactions of the Royal Society $B$, vol. 361, no. 1471, pp. 1149-1158, 2006.

[115] J. D. Salamone and M. Correa, "The mysterious motivational functions of mesolimbic dopamine," Neuron, vol. 76, no. 3, pp. 470-485, 2012.

[116] R. D. Palmiter, "Is dopamine a physiologically relevant mediator of feeding behavior?” Trends in Neurosciences, vol. 30, no. 8, pp. 375-381, 2007.

[117] P. Rada, M. E. Bocarsly, J. R. Barson, B. G. Hoebel, and S. F. Leibowitz, "Reduced accumbens dopamine in Sprague-Dawley rats prone to overeating a fat-rich diet," Physiology and Behavior, vol. 101, no. 3, pp. 394-400, 2010.
[118] I. Léna, S. Parrot, O. Deschaux et al., "Variations in extracellular levels of dopamine, noradrenaline, glutamate, and aspartate across the sleep-wake cycle in the medial prefrontal cortex and nucleus accumbens of freely moving rats," Journal of Neuroscience Research, vol. 81, no. 6, pp. 891-899, 2005.

[119] C. L. Wyvell and K. C. Berridge, "Intra-accumbens amphetamine increases the conditioned incentive salience of sucrose reward: enhancement of reward "wanting" without enhanced "liking" or response reinforcement," Journal of Neuroscience, vol. 20, no. 21, pp. 8122-8130, 2000.

[120] N. R. Richardson and A. Gratton, "Changes in nucleus accumbens dopamine transmission associated with fixed- and variable-time schedule-induced feeding," European Journal of Neuroscience, vol. 27, no. 10, pp. 2714-2723, 2008.

[121] Z. Taslimi, R. Arezoomandan, A. Omranifard et al., "Orexin $\mathrm{A}$ in the ventral tegmental area induces conditioned place preference in a dose-dependent manner: involvement of D1/D2 receptors in the nucleus accumbens," Peptides, vol. 37, no. 2, pp. 225-232, 2012.

[122] R. Sharf, D. J. Guarnieri, J. R. Taylor, and R. J. DiLeone, “Orexin mediates morphine place preference, but not morphineinduced hyperactivity or sensitization," Brain Research, vol. 1317, pp. 24-32, 2010.

[123] M. Tabaeizadeh, R. Motiei-Langroudi, H. Mirbaha et al., "The differential effects of OX1R and OX2R selective antagonists on morphine conditioned place preference in naive versus morphine-dependent mice," Behavioural Brain Research, vol. 237, pp. 41-48, 2013.

[124] J. R. Shoblock, N. Welty, L. Aluisio et al., "Selective blockade of the orexin-2 receptor attenuates ethanol self-administration, place preference, and reinstatement," Psychopharmacology, vol. 215, no. 1, pp. 191-203, 2011.

[125] C. M. Voorhees and C. L. Cunningham, "Involvement of the orexin/hypocretin system in ethanol conditioned place preference," Psychopharmacology, vol. 214, no. 4, pp. 805-818, 2011.

[126] A. R. Di Sebastiano, H. E. Wilson-Pérez, M. N. Lehman, and L. M. Coolen, "Lesions of orexin neurons block conditioned place preference for sexual behavior in male rats," Hormones and Behavior, vol. 59, no. 1, pp. 1-8, 2011.

[127] A. Tyhon, B. Lakaye, A. Adamantidis, and E. Tirelli, "Amphetamine- and cocaine-induced conditioned place preference and concomitant psychomotor sensitization in mice with genetically inactivated melanin-concentrating hormone $\mathrm{MCH} 1$ receptor," European Journal of Pharmacology, vol. 599, no. 1-3, pp. 72-80, 2008.

[128] D. G. Smith, H. Qi, P. Svenningsson et al., "Behavioral and biochemical responses to $\mathrm{d}$-amphetamine in $\mathrm{MCH} 1$ receptor knockout mice," Synapse, vol. 62, no. 2, pp. 128-136, 2008.

[129] M. J. García-Fuster, G. S. Parks, S. M. Clinton, S. J. Watson, H. Akil, and O. Civelli, "The melanin-concentrating hormone (MCH) system in an animal model of depression-like behavior," European Neuropsychopharmacology, vol. 22, no. 8, pp. 607-613, 2012.

[130] B. Borowsky, M. M. Durkin, K. Ogozalek et al., "Antidepressant, anxiolytic and anorectic effects of a melanin-concentrating hormone-1 receptor antagonist," Nature Medicine, vol. 8, no. 8, pp. 825-830, 2002.

[131] D. R. Gehlert, K. Rasmussen, J. Shaw et al., "Preclinical evaluation of melanin-concentrating hormone receptor 1 antagonism for the treatment of obesity and depression," Journal of Pharmacology and Experimental Therapeutics, vol. 329, no. 2, pp. 429438, 2009. 


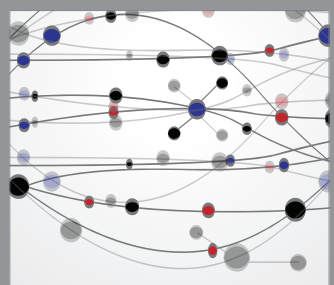

The Scientific World Journal
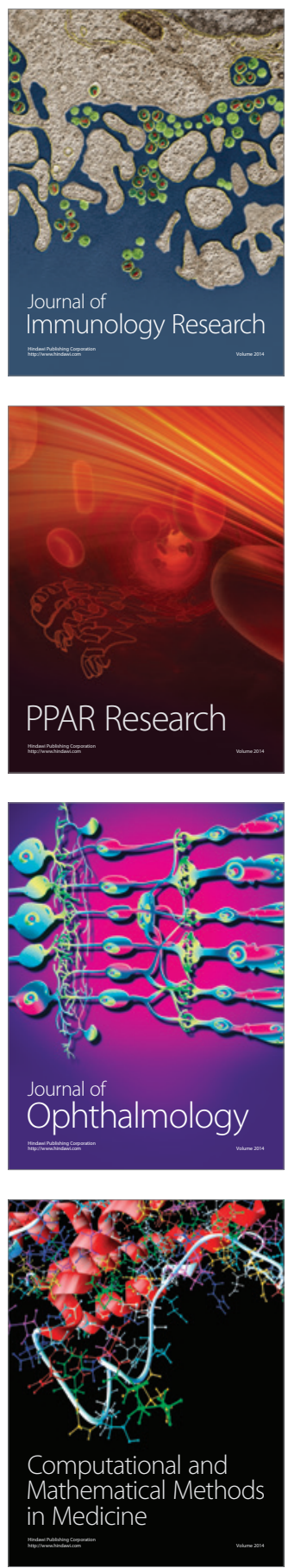

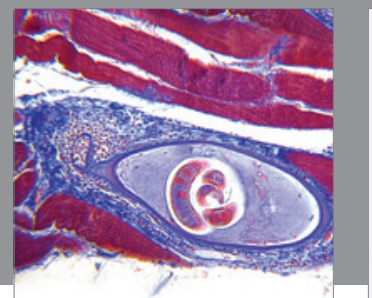

Gastroenterology

Research and Practice
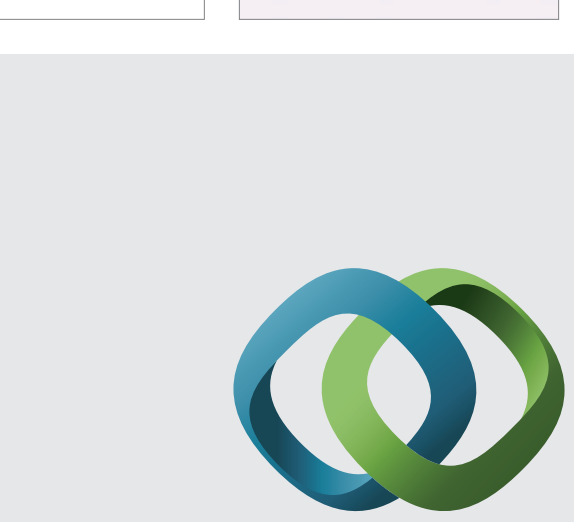

\section{Hindawi}

Submit your manuscripts at

http://www.hindawi.com
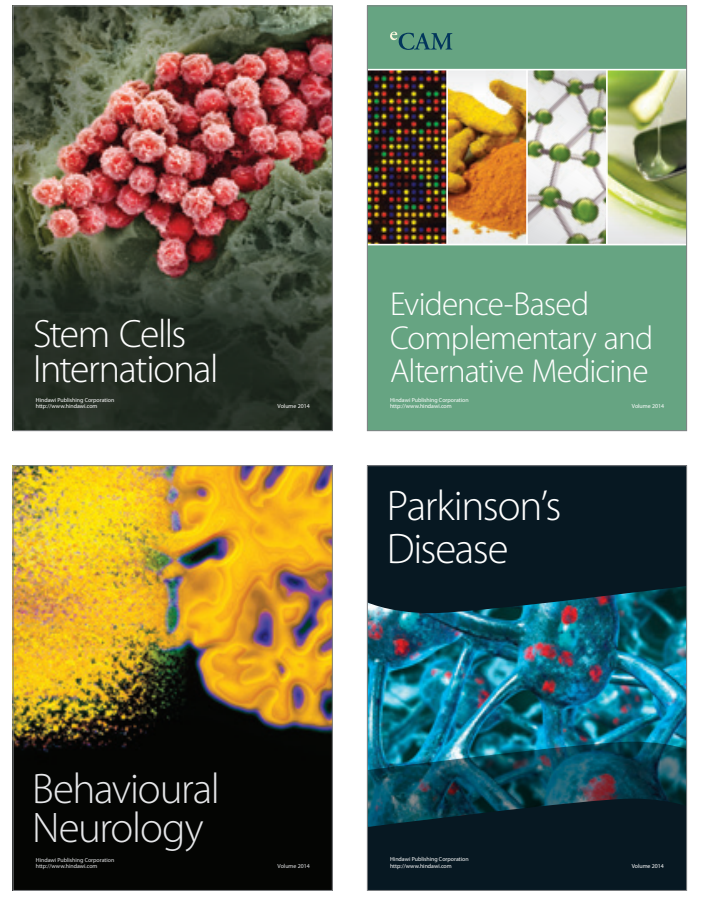
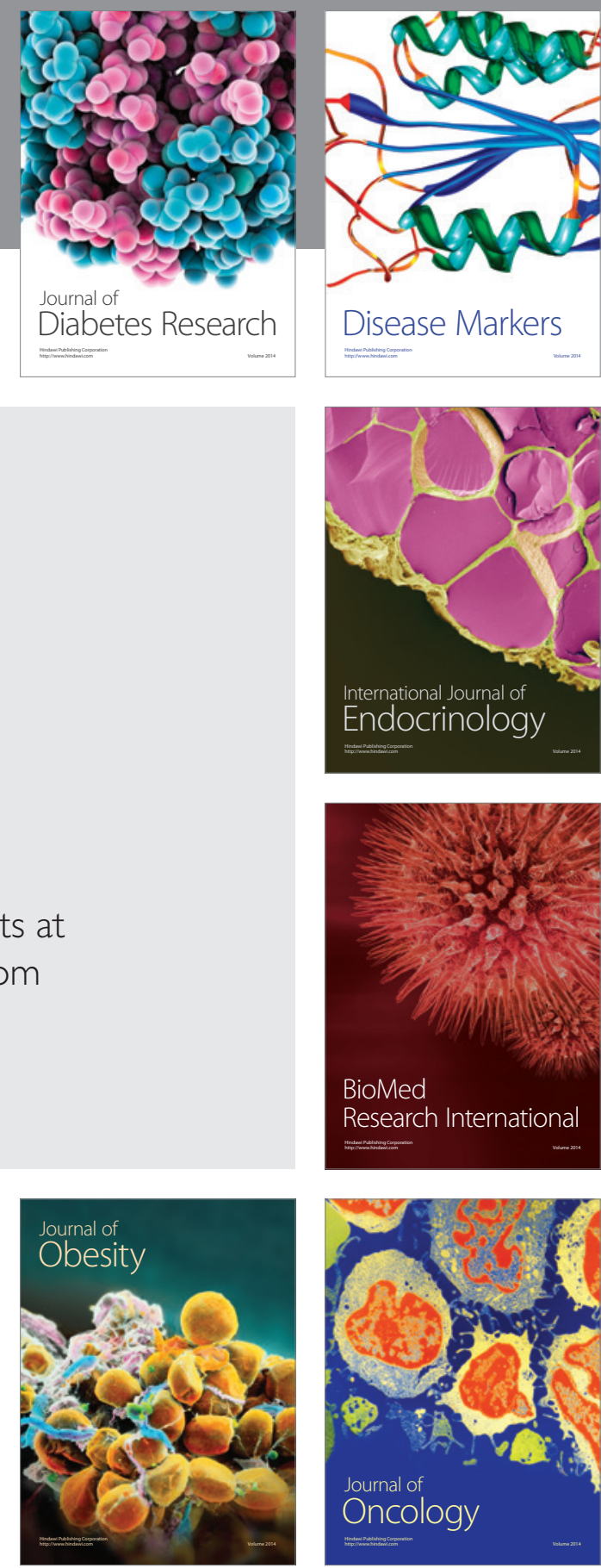

Disease Markers
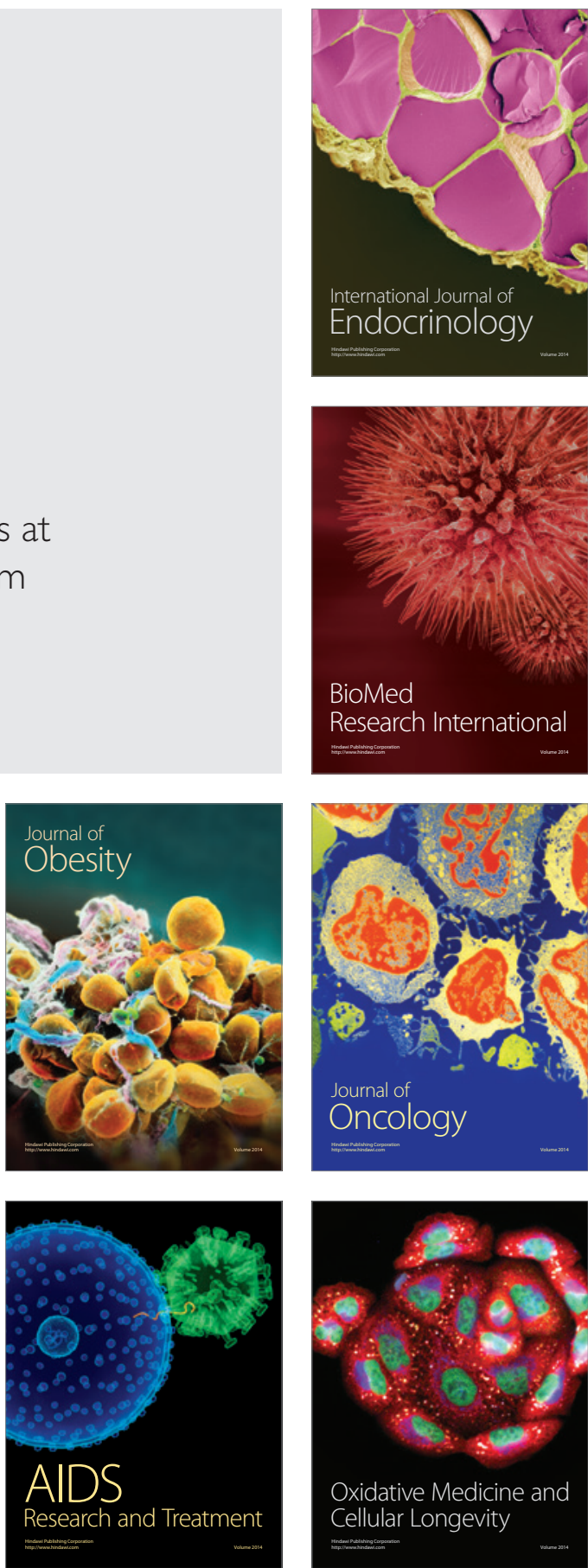